\title{
Editorial
}

\section{Achieving Consultative Party Status}

B ack in 1959 when the twelve countries that negotiated the Antarctic Treaty signed up, they made themselves Contracting (now termed Consultative) Parties, the ones with the rights to govern the continent. They had already demonstrated a significant interest in Antarctica, unlike most of the rest of the world, so not unreasonably assumed that they were best able to manage its affairs. In Article 13 of the Treaty they allowed for other interested nations to join them by acceding to the Treaty but they had already determined that there was a major difference between supporting the principles of the Treaty and having an equal say in governance. The application of Article 9 became the touchstone for progressing from Acceding to Consultative status and this says that "Each Contracting party ... shall be entitled to participate in the meetings... during such time as that Party demonstrates its interest in Antarctica by conducting substantial scientific research activity there, such as the establishment of a scientific station or the despatch of a scientific expedition".

As is so often the case with the Treaty the application and interpretation of this requirement was never defined and has gradually changed over time. The first accession to the Treaty was by Poland in 1961 but it had to wait until 1977 to be granted Consultative Status, based on its three years of research and the establishment of a station. This change in status required the Parties to establish a new system for the consideration of an application for Consultative Status from any Acceding Party including the resolution of arguments between those who wanted a literal interpretation of the clause (i.e. establishing a station or expedition gave an automatic right to be upgraded) and those who favoured a discretionary admission test. The latter won and approach adopted was on the applicant providing evidence of its scientific work, being invited to approve and implement the outstanding Recommendations and the calling a Special Consultative Meeting to discuss the case.

In 1987 the Parties returned to the discussion after urging from the United States. A three-point list of what should be provided was agreed which covered not only past science and publications but also a description of future activities and the institutions responsible for supporting the research. There was, however, still no indication of what would constitute an acceptable number of publications or commitment of resources.

One important change was agreed with the application from the Netherlands in 1990. The increasing interest in lessening environmental impacts allowed the argument that establishing a station or a national expedition should no longer be considered mandatory and applications for Consultative Status should be judged on the basis of the scientific portfolio, both past and planned. Science undertaken in co-operation with other countries was now an acceptable basis. Attempts at various points to get an opinion from SCAR on the quality of the science all failed as SCAR refused to engage in anything so overtly political. How the science qualification interacted with the political judgements was no clearer than before.

At XXXIXATCM in Santiago, Venezuela applied for Consultative Status, having presented a portfolio of its previous scientific work. The Consultative Parties considered the case and, although there was some support, the meeting declined to agree to the change in status, recommending further work before a new application. However, what did come out of the discussions was the establishment of an intersessional group to examine and possibly revise the present criteria for judging suitability for Consultative status. Perhaps now science quality and relevance will become part of the explicit criteria although they will probably have to co-exist with political considerations?

D.W.H. WALTON 